\title{
Team-based learning versus traditional didactic lectures in teaching clinical biochemistry; learning outcomes and student satisfaction: a case control study at King Abdul Aziz University
}

Aliaa A. Alamoudi ( $\square$ aaalamoudi2@kau.edu.sa )

King abdulaziz university https://orcid.org/0000-0001-5428-8853

\section{Lana Adey Alsawwa}

Department of Medical Education, Faculty of Medicine, King Abdulaziz University

Hoda Gad

Department of Clinical Biochemistry,Faculty of Medicine,King Abdulaziz University

\section{Ara Tekian}

Department of Medical Education, University of Illinois Chicago

\section{Research article}

Keywords: Team-based learning (TBL), Active learning, Clinical Biochemistry, Nucleic Acids King Abdulaziz University (KAU), Clinical Nutrition

Posted Date: September 14th, 2019

DOl: https://doi.org/10.21203/rs.2.14332/v1

License: (c) (1) This work is licensed under a Creative Commons Attribution 4.0 International License. Read Full License 


\section{Abstract}

Background: Team-Based Learning (TBL) which encourages students to become active rather than passive learners has gained world-wide popularity in medical education due to its proven positive effect on more than one aspect of the educational process. At King Abdulaziz University (KAU), clinical biochemistry is still taught in the form of didactic lectures, and while there is a need for introducing active learning, student learning response from TBL has not been explored.

Methods: In our case-control study, we compared learning outcomes and student satisfaction in a clinical biochemistry course taught either via TBL to second year Clinical Nutrition students $(n=33)$ or via traditional lectures to same year Nursing students $(n=70)$. The same summative post-course exam was given to both student groups to assess impact on learning. Focus group discussion and a self-administered questionnaire were used to gain insight into Clinical Nutrition students' level of satisfaction with TBL.

Results: In the post-course exam results of recall and reasoning questions, Nursing students scored an average of $38 \% \pm 2.4$ in the recall questions while Clinical Nutrition students scored higher with an average of $74.5 \% \pm 4.3$ $(\mathrm{p}<0.0001)$. In reasoning questions, Nursing students scored lower than Clinical Nutrition students, $23 \% \pm 2.7$ versus $40 \% \pm 4.2$ respectively $(\mathrm{p}<0.001)$. In comparing results of pre- and post-test recall questions within each group, there was no significant difference between pre- and post-results for Nursing students while Clinical Nutrition students showed a significant increase in post- versus pre-test results of $71 \%$ versus $41 \%(p<0.0001)$. In the final summative post-course exam, Nursing students scored an average of $60 \% \pm 2.4$ while Clinical Nutrition students scored significantly higher with an average of $78 \% \pm 2.4(p<0.001)$. Qualitative studies revealed that accountability and team-work were positive aspects perceived by students regarding TBL and $84 \%$ of surveyed students enjoyed the experience while self-study was their main challenge.

Conclusion: TBL proved to be a successful, learner-centered approach for Clinical Nutrition students at KAU in their clinical biochemistry course resulting in improved learning outcomes and higher student satisfaction when compared with traditional didactic methods of teaching.

\section{Background}

Despite acknowledging its importance, many students find studying biochemistry difficult a tedious sometimes describing the courses as dull. This is our experience at the Faculties Medicine and Applied Medical Sciences at King Abdulaziz University (KAU) where biochemis which is still taught in the form of didactic lectures (Alamoudi et al., 2018). Faculty membe students, and other stakeholders also acknowledge the need for a more comprehens understanding of the subject by students and improved retainment and practical application of 1 information by applying new different teaching modalities. 
Interactive learning in both formal and higher education, however, is relatively new in applicati throughout the Middle East. Students who have received their formal learning in national schools the Kingdom of Saudi Arabia (KSA) have mainly experienced passive student learning and teach centered learning. Although the increasing number of international schools in KSA and 1 curriculums they follow might expose some primary and junior high school level students to grea interactive learning, the majority of students currently enrolled in KAU have not had t] experience. Most of the students were not taught how to be interactive learners and to be activ engaged in the course material, or how to assess their own work and have a student-based learnj experience with the teacher being a facilitator more than a teacher.

One of the active learning modalities currently used in KAU is problem-based learning (PBL), wh: aims to promote student critical thinking, problem-solving abilities and communication skills allowing small groups of students to tackle real-world problems. However, this teaching methoc not utilized in the Applied Medical Sciences College in KAU. In addition, PBL, can be resource requiring a number of teaching rooms and a reasonable staff to students ratio.

Team-Based learning (TBL) on the other hand has the advantages of small group teaching a learning, but unlike PBL, does not require a large number of tutors since one tutor can cover mc than one group at a time (Hrynchak and Batty, 2012, Reimschisel et al., 2017). TBL has b€ introduced in USA universities in the last two decades, and many studies have been publisk evaluating its effectiveness in achieving several learning outcomes (Reimschisel et al., 2017).

In their review article, Patricia Hrynchak \& Helen Batty, explore the educational theory basis TBL and suggest the constructivist theory as a framework that applies to this teaching meth (Hrynchak and Batty, 2012).

According to the constructivist theory, knowledge is constructed by the learner through his/l own experiences. Learning depends on how knowledge is encoded, stored and transferred throu reflection and asking questions. New experiences modify previous understandings, thus long-te memories are continuously being reconstructed in the minds of the learners.

Although the TBL teaching method was introduced in the Middle East a few years ago, very limit studies on it are available. Only two studies have been conducted in KSA to describe the experier 
(Anwar et al., 2012, Obad et al., 2016) both of which were at the same university (Alfaisal) Riyadh. Although both studies reported a favourable impression by the students and the study Anwar et al. (2012) showed a correlation between TBL and improved final exam scores, hower such scores where compared between different cohorts and thus different exams. To c knowledge, TBL has never been implemented at the Faculty of Medicine and/or Applied Medi Sciences at KAU and as of date there is a paucity of studies in Saudi Arabia evaluating the effect its implementation on critical thinking.

\section{Aim Of Study}

The main objectives of this study were to:

-Evaluate in a case control manner if active learning through TBL could increase short te knowledge retention, and critical thinking in the clinical biochemistry course at KAU.

-Evaluate if active learning through TBL could increase students' satisfaction in the clini biochemistry course at KAU.

-Describe the perception and attitude of students towards their TBL experience.

- Determine any challenges KAU students could face with implementation of TBL.

The results of this study could identify successful elements from the implementation of TBL a clarify any areas that would still need to be modified for other courses and other students in 1 medical and applied sciences fields.

\section{Methodology}

\section{Design and participants of the study}

Second year Nursing students $(n=33)$, Faculty members of Nursing, second year Clinical Nutritj students $(n=70)$, and Faculty members of Applied Medical Sciences were all part of this stuc Both groups of students received the same course of Clinical Biochemistry (BCHM 207), wh: covered basic cell metabolism, bioenergetics and molecular biology and which was given by 1 same teaching staff. In a case-control manner, the same tutor (Dr. Aliaa Alamoudi) taught the sa: 
Nucleic Acid (NA) section of the Clinical Biochemistry course to both groups of students. Howev the Clinical Nutrition group of students were instructed in the form of a TBL session, while 1 Nursing students were instructed through traditional didactic lectures. Both groups consisted o: of female students, and there were no male students in either faculty, thus limiting some of 1 variables and differences that could have existed between female and male departments.

Both groups had successfully completed the same preparatory year, a requirement by the $\mathrm{K}$ Ministry of Education, before being considered eligible to continue their bachelor qualificatj studies starting the second year. In addition, both groups showed similar entry level grades their second year.

To test and ensure the equity between both groups prior to the study, students were asked to subl at the beginning of their second bachelor studies year, their university entry exam scores of Qij which includes the General Aptitude Test (GAT) and the Scholastic Achievement Admission T (SAAT), and the GPA of their preparatory year. A description of each of these tests and 1 students' entry exam scores is described below.

Qiyas tests:

Given the variety of teaching formats and curricula in KSA schools and to ensure equity a fairness upon university admissions, The National Centre for Assessment (Qiyas) was established a separate entity to conduct standardised tests in KSA as a criterion for university admissi besides the secondary school certificate results. Two main tests are mainly given by Qiyas : the G and SAAT. .

The GAT is a 120- question test that uses mathematical and verbal skills.

According to Qiyas, scores are analyzed as follows: 


\begin{tabular}{|l|l|}
\hline Student's positionest score \\
\hline Top 5\% & 81 and aboye \\
\hline Top 10\% & 78 and aboye \\
\hline Top 20\% & 73 and aboye \\
\hline Top 30\% & 70 and aboye \\
\hline The average & 65 and aboye \\
\hline Lowest 30\% & 60 and below \\
\hline
\end{tabular}

The SAAT test on the other hand measures the overall achievement of students during their wh education journey. The test covers key concepts in biology, chemistry, physics, math and English the form of multiple-choice questions (MCQ's) which are divided equally between the five subje and is scored out of 100 .

\section{NA section lectures}

The NA section of the biochemistry course was given to the control arm of this study (Nursi students) in the form of traditional lectures. The section was taught via five lectures and a tutori covering: NA structure, DNA replication, Gene transcription, Post-transcription modification a Gene translation. Each lecture was given as a 60-minute power-point presentation to the stude: by Dr. Aliaa Alamoudi, and consisted roughly of 30-40 slides. Each lecture started with 1 expected student learning outcomes, a video related to the topic, text, graphs, and some questic related to the topic addressed. Attendance was not taken from students, however, it was estimat to reach around $70 \%$. All lectures were given in a lecture hall, which had a capacity of around 2 students and was furnished with audiovisual equipment.

\section{TBL session design:}

The Clinical Nutrition group of students on the other hand were instructed the NA part of 1 course via a single TBL session. A description of all the aspects of the TBL session is described the sections below. 


\section{TBL orientation workshop}

To ensure the readiness of the second year Clinical Nutrition students to be engaged in TBL, th attended a two-hour TBL orientation workshop. The students were first asked to reflect (in pai on the advantages and disadvantages of traditional lectures and their findings were then discuss amongst all of them. A video demonstrating the experience of TBL in other universities was tr played. Afterwards, students were introduced (via a power-point presentation) to a detai. overview of TBL including: background, the pre-reading step, the Individual Readiness Assurar Test (IRAT), the Team Readiness Assurance Test (TRAT), scoring system, references, etc. Fina. students were asked to reflect on the anticipated advantages and disadvantages of introducing $\mathrm{T}$ and any queries from the students were addressed.

\section{TBL Team formation:}

Second year Clinical Nutrition students were divided based on their previous two clini biochemistry quizzes scores into ' $\mathrm{A}$ ', ' $\mathrm{B}$ ', and ' $\mathrm{C}$ ' students. Students were then divided into groups of 5-7 students per group with each group containing equal numbers of 'A', 'B', and students. The students were distributed to their teams prior to the TBL in-class session.

\section{TBL Pre-class reading}

Prior to class, students were allocated compulsory readings and five power-point lectures. Ec lecture was accompanied by the required student learning outcomes, detailed content, vidt related to the topic, chapter of the required reference, and two to three assessment questions. the material was uploaded on the blackboard online system ten days prior to the TBL in-cli session. Students were informed that they could use the time slot allocated for their lecture time the students' time table for their pre-class reading whether in class or at the campus library with any tutor supervision. 
The structure of the TBL in-class session was divided into the IRAT, TRAT, and problem- solvi activities. The IRAT was given at the beginning of the session to assess the individual's knowlec of the pre-reading. The test was provided as $10 \mathrm{MCQs}$ with four options to select the single $\mathrm{b}$ answer, and was given in 15 minutes. This was followed by the TRAT, in which the same test $n$ repeated by the students in their teams in order to promote discussion and allow team-work reaching the consensus. The TRAT was conducted in 30 minutes. Teams who answered correctly their first attempt received 4 points, while those who answered correctly on second atten received 2 points, and 1 point was given to those who answered correctly on their third attempt each question. The TRAT test was given as a scratch-off form, which provided the students with 1 answers of each of the questions immediately. A small summary of the answers was provided by 1 tutor after the end of the TRAT, and explanation was provided to address any difficult questio Although a formal appeal process was not provided, the discussion was opened to allow students challenge answers and ask questions. The final 30 minutes of the TBL session was used in proble solving activities by the team. The teams received three problem (case scenario) activities, allowi them to apply conceptual knowledge on relevant cases or scenarios that fit with the specialty their studies. Each case scenario had four possible answer choices for the teams to select the b

answer. All cases followed the standard ' $4 \mathrm{~S}^{\prime}$ ' framework in TBL, in which all cases were 'Significant problem', 'Same problem for all teams', 'Specific choice', and finally teams provic 'Simultaneous report'.

TBL marks were divided as follows: 2 marks for attendance, 5 marks for the IRAT, 5 marks TRAT and 3 marks for the case activity. The overall TBL session score was calculated out of marks and was considered as the third continuous assessment in the biochemistry course besic Quiz 1 (15 marks) and Quiz 2 (15 marks). Students were informed that the highest two marks ( of the three assessments would be included as continuous assessment marks (30 marks) out of th total 100 marks in the course. .

\section{Pre- and Post-course Test}

In order to ensure that both groups had a similar background in molecular biology befc implementing our TBL experiment, a pre-course test was conducted for both groups. The test $n$ in the form of 15 recall MCQs and was provided by a colleague member of the clinical biochemis department to avoid any bias. The test was conducted by the Clinical Nutrition students prior to 1 
start of the TBL workshop, and by the Nursing students prior to the beginning of their first ] lecture.

To evaluate whether TBL was able produce improved student comprehension of the subject, a whether the learned information was better retained and applied, a post-course test was conduct for both groups. Similar to the pre-course test, the post-course test was a 15 MCQ test that $\mathrm{h}$ both recall and reasoning dimensions and was constructed by three colleague members of 1 clinical biochemistry department who were not involved with this study or any of the NA lectures TBL design to avoid any bias.

The test was given to both groups as a pop quiz a week after the end of both the NA lectures a TBL

\section{Final Biochemistry (BHCM) course exam and NA section exam}

At the end of the term, both groups received a final summative exam made of a total of $60 \mathrm{MC}$ based on a blue print covering all the term's BHCM course material (protein structure, enzym carbohydrate metabolism, lipid metabolism, amino acid metabolism and finally NA). The exam $n$ a three-hour exam, in which students are allowed to submit their papers after one hour and a hi The same 9 NA MCQs were used in both exams and the scores of both groups in these 9 questic were then compared.

\section{Focus group interview:}

One of the main aims of this study was to gain more insight into Saudi students' impression of 1 TBL experience, as there was not an abundance of pre-existing data regarding their experier with this method of teaching. We thought that understanding students' opinions, beliefs a disparities could help us in bridging the research results on TBL with its actual implementation our curricula at KAU in the future thus facilitating a smoother transition.

Thus to explore the experience of students in depth, a sample of students were invited (af obtaining their verbal consent) to participate in a semi-structured interview in a focus gro 
meeting setting. The overall objective of the focus group meeting, the time and place, the intenc themes for discussion, and the method of recording were all discussed with members of 1 medical Education Department prior to involving the students.

A purposive sampling of students was conducted based on the students' results in the TBL sessi Students were divided into 3 categories according to their TBL session scores: high-scori] average-scoring or low-scoring, and two students were chosen randomly from each of the categories. All students were invited verbally to attend the focus group discussion after describj to them the main objectives of the discussion.

The focus group discussion was conducted at the Medical Education Department in the presence Dr Aliaa Alamoudi and Dr Lana Alshawwa. The aim of the focus group discussion was fi explained to the students and included:

1) Knowing about their experience in TBL

2) Guidance in conducting the student survey

Verbal consent was taken from all students to record them. The semi-structured interview consis of a set of pre-defined open-ended questions which addressed the students' overall level satisfaction with the TBL experience, the advantages and challenges of TBL in their opinion a whether the experience changed the way they studied.

Based on the students' response to these pre-defined questions, the interviewers were able diverge to pursue an idea in greater detail. Students were allowed to express their thoughts Arabic or English. However, most of the interview was conducted in Arabic.

\section{TBL Survey.}

To evaluate all the Clinical Nutrition students' $(n=33)$ perspectives on their TBL experience a : question on-line survey with an additional three, open-ended questions was constructed based themes that emerged from the earlier focus group meeting discussion. The survey questions wt revised by local and national experts in medical education. To ensure the clarity of the suri content and to ensure its validity, it was first tested out by a small focus group of students befc 
being distributed to all participants via email. The survey was divided into sections as described Table 1.

Table 1.

\section{Data and Statistical analysis}

Exams scores were analysed and presented as mean \pm SD using GraphPad Prism version 5.0 Windows, GraphPad Software, La Jolla California USA. Students' T test was used for testin! significance. A value of $\mathrm{p}<0.05$ was taken as a cut-off value for significance. Qualitative data ani was done through classification, determination of themes, and linking to present literature

\section{Results}

\section{Comparing entry exam scores for Clinical Nutrition and Nursing students}

When comparing GAT scores between the Clinical Nutrition and Nursing students, we could see that both groups fell in the Top $5 \%$ with a mean of $84.4 \%$ and $81 \%$ respectively $(\mathrm{p}<0.001)$ (Fig.1).

When comparing SAAT scores between the two groups, the Clinical Nutrition students scored $87.5 \% \pm 0.8$ and the Nursing students scored and $84.3 \% \pm 0.5$ respectively $(p<0.001)$ (Fig. 1$)$.

In this study, both groups showed a close GPA mean, with Clinical Nutrition students scoring $4.96 \pm 0.007$, while Nursing students scored $4.86 \pm 0.008$ (Fig.1).

Figure 1.

\section{Comparing Pre-Post course NA test results between Clinical Nutrition and Nursing students}

There was no significant difference between the results of each group of students in the precourse test. However, the Nursing students showed a higher percentage mean of $46 \% \pm 2.4$ compared to $41 \% \pm 2$ for Clinical Nutrition students (Fig. 2). Overall this indicated that both groups showed similar basic knowledge on NA topics. 
As mentioned earlier, the post-course test was a $15 \mathrm{MCQ}$ test that had both recall and reasoning dimensions. Nursing students scored an average of $38 \% \pm 2.4$ in the recall questions while Clinical Nutrition students scored an average of $74.5 \% \pm 4.3(\mathrm{p}<0.0001)$. Similarly, Nursing students showed a lower percentage in the reasoning questions $23 \% \pm 2.7$ compared to $40 \% \pm 4.2$ for Clinical Nutrition students $(\mathrm{p}<0.001)$ indicating that TBL did enhance the retention of knowledge and resulted in better understanding of the material (Fig.2).

Figure 2.

\section{Pre- and Post-course NA test results for Clinical Nutrition and Nursing students}

To further evaluate the effect of TBL, pre- and post-test (recall sections) results were compared within each group. While there was no significant increase in post-test results for Nursing students with a mean of $38 \%$ compared to $47 \%$ for their pre-test results, Clinical Nutrition students showed a significant increase in their post-test results with a mean of $71 \%$ compared to $41 \%$ for their pre-test results $(\mathrm{p}<0.0001)$ (Fig.3).

Figure 3.

\section{NA final exam results for Clinical Nutrition and Nursing students}

To further evaluate whether TBL had enabled students to acquire factual knowledge of the course and achieve better understanding of the material, we compared the results of both groups in the final exam's NA questions.

While Nursing students scored an average of $60 \% \pm 2.4$ in these questions, Clinical Nutrition students achieved a significantly higher score, with an average of $78 \% \pm 2.4(p<0.001)$ (Fig.4).

Figure 4.

Clinical Nutrition students' perspective on TBL experience and results of the focus group discussion 
The six focus group discussion students were first asked about their overall impression on the TBL experience. The group agreed that it was a very good experience and concept, which enhanced their ability to depend on themselves in studying. All of the members of the group stated that they enjoyed specifically the TRAT.

The group was then asked specifically if they could pinpoint why they thought it was a good experience. Five main themes emerged from their responses: 1- variety of learning material, 2team-solving discussion, 3- accountability and self- directed learning (SDL), 4- grade distribution, 5- preparation for final exam.

To further elaborate, students felt that they were not confined or limited in the material from which they could study. They liked the fact that accessing the educational video-links sent to them by the instructor led them to access and watch other interesting, beneficial, educational videos. The fact that the original educational videos were selected and made available by the instructor herself, made the students feel comfortable and confident of the usefulness and trustworthiness of the resources; something which they were not sure of when they chose their resources alone.

All students agreed that the team-solving discussion was an excellent experience, and they felt that there was more retention of knowledge stemming from this exercise. Peer-to-peer discussions provided them the opportunity of sharing information amongst themselves in a simplified manner. When asked specifically if this team activity helped them connect more with their classmates, students expressed that the TBL session led to them knowing their other classmates better, an opportunity which might not have been provided otherwise, and that all-inall they enjoyed working in teams.

The third point that emerged from the group discussion was accountability and responsibility. All students agreed that they felt a great sense of responsibility and trust towards their team members during the TBL's TRAT. Although some students acknowledged the importance of selfdirected and independent learning and thought it was one of the advantages of the TBL, others felt that it was a difficult process for the students and could be one of the drawbacks of TBL for them. 
One of the interesting points that emerged from the focus group discussion was grade distribution. Students felt pleased that there was more flexibility with the grading distribution since the marks were divided between the IRAT, TRAT, and group activity. In addition, students enjoyed the fact that the TBL's TRAT gave them more than one chance to try to answer correctly and still get marks. They also felt that the TBL gave them the opportunity to enhance their marks without actually being under the pressure of a summative exam.

Finally, students felt that the TBL prepared them better for the NA section of the exam course, that they understood the material well and that they needed less time to study before the final exam.

The group was then asked to reflect on the challenges and/or disadvantages they experienced during the experience. Two main points emerged from the discussion. First, students stated that, at times, it was difficult to study and understand the material on their own. Most of the group agreed that they would have preferred additional texts to explain the material.

Second, students sensed that there was limited time to prepare for the TBL, especially since it was conducted at the end of the academic term. The group was asked on how they utilized their material preparation time slots set in the time-table. Students replied that unfortunately the time slots weren't used for material preparation, but rather utilized by tutors for other subjects to be able to finish any remaining curriculum before the end of term. They felt that this occurred mainly because there was no supervision from tutors during these preparation sessions. Thus, all the studying and learning related to preparation for TBL was done at home after class hours, which they felt was an extra load on them. Also, one student commented that the time allotted to do the IRAT was too short while another stated that the activity cases were difficult with a lot of depth and perhaps above their level.

When the students were asked about their preparation for the TBL session and whether they understood in general what was required from them, they all agreed that the objectives, videos, 
and word document containing detailed content for each lecture were very clear for them and that they came away from the TBL workshop understanding exactly what was expected of them. When asked if they studied the material on their own or in groups, they replied that some students studied the material in groups while others studied on their own. They also mentioned that a Whatsapp group was started and that gave them the opportunity to discuss difficult or unclear points amongst themselves. However, one student mentioned that she couldn't predict how the IRAT would be and that although she felt that she had studied hard assuming she would be able to achieve a full mark in the test, in the end she didn't.

When the students were asked how the preparation could be improved, students replied that giving them the material in advance from the beginning of the term could help, and that some sort of a formative exam before the IRAT and the application cases would be useful to prepare them for the questions.

For the sake of the future implementation of TBL, we asked students if they had used or would in the future use TBL as a method of learning or studying in other courses. They stated that so far they had not had a chance to use it since they were introduced to it was towards the end of the term. However, they thought that they would use it for other courses in the future since they found it to be a very valuable and good experience which increased their ability and confidence to study on their own. One student mentioned that she would implement it, but that she we would need to understand the way to study and what the nature of the questions would be. Another student stated that the students were bored of conventional ways of teaching and spoonfeeding, and that she would recommend that TBL be introduced at least once a term after which students could decide whether they wanted to continue with TBL or not. When asked which parts of the TBL the students felt they would adopt for their learning methods, they agreed that it was team-solving activities and using educational material such as watching videos.

The final part of this group discussion focused on attitudes and beliefs. Upon asking students if they believed in the value of team-work, all of them agreed on its importance.

We also asked the students if this TBL experience had changed anything in the way they studied and the phrase "depth of learning" was mentioned several times by most of the group members wherein students agreed that TBL made them understand the importance of understanding the material in depth and that they needed to allocate more study time to achieve this. 
Finally, we asked the students if they felt that they retained the knowledge learnt with the TBL experience more than with the conventional teaching technique. Most students replied affirmatively saying that they still remembered some of the information from watching the videos and from the team discussion. Only one student said that she couldn't recall the information she had learnt but she said it was because she hadn't studied very well.

At the end of the group discussion, students were thanked for their contribution, and were commended for their courage in participating in this new experience.

\section{Clinical Nutrition students' perspective on TBL experience}

To explore the perspectives of all the Clinical Nutrition students towards the whole TBL experience, we conducted a survey that covered points that had emerged from the focus group discussion. Survey results are summarized in Table 2. Overall $84 \%$ of students stated that they enjoyed their TBL experience with $69 \%$ finding it to be more fun and $58 \%$ finding it to be more beneficial than lectures. $68 \%$ of the students stated that they would like to repeat the experience. Notably, all the students (100\%) enjoyed solving problems together in teams. As expected, a high percentage of students (84\%) stated that they enjoyed watching related video materials and $68 \%$ found that they understood better with peer-teaching. Interestingly, though, while $64 \%$ felt like they remembered the information more with TBL than with lectures, only $31 \%$ felt they understood the material better with TBL. 95\% of the students preferred to have had supervised and scheduled sessions in the time-table for material preparation, and a high percentage (89\%) preferred to have received the material earlier.

\section{Discussion}

In this case-control study we introduced the first applied TBL model in the faculty of Applied Medical Sciences in KAU aiming to evaluate whether the TBL experience could enhance critical thinking, improve knowledge retention and increase student enjoyment in Clinical Biochemistry courses. 
Learning outcomes is one of the most commonly studied aspects of TBL (Fatmi et al., 2013, Reimschisel et al., 2017). However, as described previously, most of the studies on TBL have been conducted in the USA. In addition, a very limited number of studies have been conducted addressing the benefits of TBL for students who are not studying medicine (Fatmi et al., 2013, Reimschisel et al., 2017).

A few studies have shown that TBL had a positive effect on student examination performance. For example, $2^{\text {nd }}$ year Medical students in Wright State University achieved higher scores on examination questions related to content introduced via TBL than on content introduced by other methods (Koles et al., 2010). Similarly, TBL was more effective than small-group teaching in the achievement of knowledge objectives of three clinical topics in a clinical clerkship (Thomas and Bowen, 2011).

Interestingly, several studies have shown that TBL can better benefit students with lower academic performance than those with higher academic performance (Kang et al., 2016, Koles et al., 2010).

Many aspects in TBL can explain the demonstrated improvement in learning outcomes. First of i IRAT exams motivate students to come well-prepared and to read the material beforehand. Durj team discussions in TRAT and application cases, any gaps of knowledge can be exposed, and per explaining to their team members can help minimize these gaps. In addition, the immedii availability of correct answers during the TRAT can help faculty to quickly detect difficult conce: and to clarify the; something which is not guaranteed to occur during traditional lectures. F teams to reach consensus during TRAT and application activities, the students need to learn how listen to each other, communicate, and negotiate. This ultimately makes them more engaged $\mathrm{w}$ their material (Koles et al., 2010). All these elements fulfill Michaelsen's conceptual framework which learners' engagement lies at the core of the educational process (L. and M., 2008).

The impact of TBL on the students' engagement in this study was reflected in the students' recorc perceptions during the focus group discussion. Students stated that since the pre-reading mater contained figures and not only text, they felt the need to engage more in understanding 1 information given by the figure. In addition, students reported that during team discussions me 
learning gaps were exposed and that they found it easier to comprehend from a peer explaining 1 material (since they used simpler terminology) than if a teacher had explained. This fits with 1 cognitive congruence hypothesis in peer teaching, in which it is believed that the closer the level knowledge a teacher has with the students (i.e congruence) the more effective the teacher is ( $\mathrm{T}$ Cate and Durning, 2007). In this setting, the peer teacher understands and relates more to 1 difficulties that other student peers face, and thus can explain hard concepts in a manner that per can grasp. (Ten Cate and Durning, 2007).

Students also felt that having several elements contribute to the TBL grade (attendance, IR $f$ TRAT and group activities) alleviated the pressure on them because it increased their chances gaining points. Students also stated that they were very motivated to do well in the TBL session they knew that the TBL grade could be included in the best two of three grades in place of one the two quizzes they'd taken previously. This indicated that the timing of introducing TBL could an important factor that could help motivate students to actively engage in it.

When asked about the challenges they faced, students agreed that one of the main challenges $n$ the difficulty of studying the material on their own especially that they felt there was limited time study. There are different forms of active learning that not only ensure students' engagement ] help to effectively prepare students with skills useful for their future careers. Self directed learnj (SDL) for example, was described by Kowles as a process led by the individual which incluc identifying their learning needs, setting a plan to achieve it, and evaluating and measuring th own learning outcomes (Boyer et al., 2014). In a culture in which students have not been exposed being in charge of their own learning process, extra support and resources might be required implement active learning, including SDL. It might be important, therefore, to have lectures t] introduce students to the concepts and models of active learning before formally implementing TH Instructors might specifically need to fulfill the role of coaches to help students in this proci (Boyer et al., 2014). Students need to be guided on how to select educational resources they thi they need to fulfill their learning objectives and also on ways to measure their learning outcomes.

In the focus group discussion, students stated that the preparation time slots set in the time ta: weren't used for TBL material preparation but for studying other subjects. In the futı implementation of TBL, therefore, it would be important not just to set time slots during the ti: table for students to read the TBL material and prepare, but equally important would be t] 
these time slots be under the supervision of the instructors or facilitators to ensure that they a used solely for this purpose.

One of the key elements of a successful TBL is incorporating an application exercise that c promote critical thinking and ensure students' engagement. Application exercises are of considered the most challenging aspects of TBL. A useful way to achieve this is to use the backwe design when designing the course, and the application exercises. The instructor should think abc what skills and knowledge their students should acquire and have by the end of the course a accordingly create exercises with practical problems that the students could encounter in their lir as health professionals. It is therefore not enough to ask what information should Clinical Nutritj students know about molecular biology, but also why would they need to know it, and how woulc help them in their future career. Ideally, the designing of beneficial application exercises wor entail proper engagement from various departments and/or different stakeholders and wo require more time and a clear cooperation process which would require the support of sen administration (heads of departments, vice-deans, and deans).

Assignments not only need to promote learning but to also ensure in-depth group interaction which assures students' engagement. Very importantly, the assignments should enhance critical thinking, analysing and high-order thinking as described in Bloom's revised taxonomy (Michaelsen and Sweet 2008). What could contribute to this is the evoking of interactive discussions between students by providing assignments with a set of various solutions each of which could be plausible to an extent.

It is therefore crucial to ensure that the staff designing the TBL can develop effective assignments and discern between effective versus ineffective ones. It is essential that training workshops addressing specifically this important aspect of TBL are conducted for faculty members.

Although we attempted to limit as much as possible the variables between the two cohort students in our study by selecting students in their same study year ( $2^{\text {nd }}$ year bachelor studies), having the same tutor teach the same NA material, and by giving the same set of post-cous questions to both groups, however, the existence of other variables could have limited the valid 
of the results of this study. For example, other courses being taught simultaneously to the studer other tutors teaching them, and the overall motivation and morale of each group.

\section{Conclusions And Recommendations}

TBL proved to be a successful, learner-centered approach for Clinical Nutrition students at KAU their biochemistry course resulting in improved learning outcomes and higher student satisfactj when compared with traditional didactic methods of teaching.

Accountability and team-work were two main positive aspects of TBL perceived by students in this study in alignment with Parmelee and Michaelson's (2010) framework for TBL. The ability to self-study was the biggest challenge students faced in implementing TBL and preparing the students well prior to the TBL was a key element for the success of the experience.

In the future, TBL can be introduced as an alternative teaching modality in the Faculty of Medicine and Applied sciences in KAU to overcome some of the disadvantages of didactic lectures and to enhance students' engagement. TBL would be especially appealing in settings in which there are challenges (such as the need for high faculty/student ratio, the need for multiple teaching rooms, and the short duration of some courses) that preclude the implementation of other group-teaching methods. 
1- Introduction of practical, hands-on TBL workshops for faculty members and students is important and recommended to educate them on the important aspects and procedures required to successfully implement TBL. 2- University stakeholders should invest in teaching students self-directed learning skills as this can motivate them in enhancing their confidence to study on their own and in overcoming any fears or doubts they may have when exposed to new active-learning teaching modalities. 3-A multidisciplinary approach should be used when designing the courses and application cases in TBL to ensure that applicable and relevant material is introduced to students, and that the cases represent real-life problems which they could face in their future career. 4- Workshops on effective application assignment design using the ' $4 S^{\prime}$ ' principle should be conducted for teachers of TBL.

\section{References}

ALAMOUDI, A., HASSANIEN, M., AL SHAWWA, L., BIMA , A., GAD, H. \& TEKIAN, A. 2018. Introducing TBL in Clinical Biochemistry: Perceptions of Students and Faculty MedEdpublish, 7.

ANWAR, K., SHAIKH, A. A., DASH, N. R. \& KHURSHID, S. 2012. Comparing the efficacy of team based learning strategies in a problem based learning curriculum. APMIS, 120, 71823.

BOYER, S. L., EDMONDSON, D. R., ARTIS, A. B. \& FLEMING, D. 2014. Self-Directed Learning:A Tool for Lifelong Learning. Journal of Marketing Education, 36, 20-32.

FATMI, M., HARTLING, L., HILLIER, T., CAMPBELL, S. \& OSWALD, A. E. 2013. The effectiveness of team-based learning on learning outcomes in health professions education: BEME Guide No. 30. Med Teach, 35, e1608-24.

HRYNCHAK, P. \& BATTY, H. 2012. The educational theory basis of team-based learning. Med Teach, 34, 796-801.

KANG, K. A., KIM, S. J., OH, J., KIM, S. \& LEE, M. N. 2016. Effectiveness of simulation with team-based learning in newborn nursing care. Nurs Health Sci, 18, 262-9.

KOLES, P. G., STOLFI, A., BORGES, N. J., NELSON, S. \& PARMELEE, D. X. 2010. The impact of team-based learning on medical students' academic performance. Acad Med, 85, 1739-45.

L., M. \& M., S. 2008. The essential elements of team-based learning. New Directions for teaching and learning 7-27.

OBAD, A. S., PEERAN, A. A., SHAREEF, M. A., ALSHEIKH, W. J., KALAGI, D. A., ALAMODI, A. A., KHAN, T. A., SHAIKH, A. A., GANGULY, P. \& YAQINUDDIN, A. 2016. Assessment of first-year medical students' perceptions of teaching and learning through team-based learning sessions. Adv Physiol Educ, 40, 536-542. 
REIMSCHISEL, T., HERRING, A. L., HUANG, J. \& MINOR, T. J. 2017. A systematic review of the published literature on team-based learning in health professions education. Med Teach, 39, 1227-1237.

TEN CATE, O. \& DURNING, S. 2007. Peer teaching in medical education: twelve reasons to move from theory to practice. Med Teach, 29, 591-9.

THOMAS, P. A. \& BOWEN, C. W. 2011. A controlled trial of team-based learning in an ambulatory medicine clerkship for medical students. Teach Learn Med, 23, 31-6.

\section{Abbreviations}

KAU : King Abdulaziz University

TBL: Team-Based Learning

KSA: Kingdom of Saudi Arabia

PBL: Problem-Based Learning

MCQ : Multiple Choice Question

IRAT: Individual Readiness Assurance test 
TRAT: Team Readiness Assurance test

SDL: Self-Directed Learning

NA: Nucleic Acid

GAT: General Aptitude Test

SAAT: Scholastic Achievement Admission Test

\section{Declarations}

\section{Ethics approval and consent to participate}

Ethical approval was obtained from the Biomedical Research Ethical Committee at the Faculty Medicine (FOM) at KAU. In addition, students were given relevant information on the study a verbal consent was obtained prior to any interviews.

\section{Consent for publication}

A recorded verbal consent was obtained from participating students prior to focused group discussion. Recorded verbal consent is available from corresponding author upon request.

\section{Availability of data and material}

The datasets used and/or analysed during the current study are available from the corresponding author on reasonable request.

\section{Competing interests}

The authors declare that they have no competing interests.

\section{Funding}

The author(s) received no specific funding for this work. 


\section{Authors' contributions}

Aliaa Alamoudi, MD, PhD, is an Assistant Professor in the Department of Clinical Biochemistry at King Abulaziz University (KAU). Dr. Alamoudi conceptualized and designed the study, acquired and interpreted the data, drafted the initial manuscript, revised the manuscript, and approved the final manuscript.

Lana Al Shawwa, $\mathrm{PhD}$ is Associate Professor in the Department of Medical Education in the Faculty of Medicine at KAU. Dr. Al Shawwa contributed to the conceptualization and revision of the manuscript conducting and analyzing focused group data.

Hoda Gad, $\mathrm{PhD}$, is an Associate Professor in the Department of Clinical Biochemistry at King Abulaziz University (KAU). Dr. Gad contributed in designing the TBL for the study and in interpreting the data.

Ara Tekian, PhD, MHPE is Professor in the Department of Medical Education at the University of Illinois College of Medicine at Chicago. Dr. Tekian contributed to the conceptualization and revision of the manuscript 


\section{Tables}

Table 1. Clinical nutrition students' TBL experience survey

\begin{tabular}{|l|l|}
\hline Section & NO of Questions \\
\hline Overall experience & 4 \\
Setup & 5 \\
Advantages & 13 \\
Disadvantages & 5 \\
Future implementation \\
Attitude and beliefs & 2 \\
Open ended questions3 \\
\hline
\end{tabular}


Page 26/31 
Table 2. Clinical nutrition students' perspective on TBL experience

\begin{tabular}{|c|c|c|c|}
\hline & $\begin{array}{l}\text { \% Strongly } \\
\text { agree/agree }\end{array}$ & $\begin{array}{c}\text { \% Strongly } \\
\text { disagree/disagree }\end{array}$ & \%Neutral \\
\hline Enjoyed TBL experience & 84 & 0 & 16 \\
\hline TBL more fun than lectures & 69 & 5 & 26 \\
\hline TBL more beneficial that lectures & 58 & 21 & 21 \\
\hline Like to repeat the experience & 68 & 11 & 21 \\
\hline TBL steps were clear & 79 & 5 & 16 \\
\hline Objectives and given material were clear & 100 & 0 & 0 \\
\hline $\begin{array}{l}\text { Preferred to have more material explanation in } \\
\text { PPT }\end{array}$ & 74 & 5 & 21 \\
\hline $\begin{array}{l}\text { Preferred to have a formative exam prior to TBL } \\
\text { session }\end{array}$ & 72 & 17 & 11 \\
\hline Preferred to receive material earlier & 89 & 11 & 0 \\
\hline Enjoyed solving together in teams & 100 & 0 & 0 \\
\hline Enjoyed studying together in teams & 73 & 16 & 11 \\
\hline Enjoyed having different material to study from & 69 & 5 & 26 \\
\hline Enjoyed watching video material & 84 & 5 & 11 \\
\hline Enjoyed self studying & 58 & 26 & 16 \\
\hline Understood more with peer teaching & 68 & 21 & 11 \\
\hline $\begin{array}{l}\text { Felt like you understood material more with TBL } \\
\text { than lectures }\end{array}$ & 31 & 37 & 32 \\
\hline $\begin{array}{l}\text { Felt like you remembered the information more } \\
\text { with TBL than with lectures }\end{array}$ & 63 & 11 & 26 \\
\hline $\begin{array}{l}\text { TBL taught you how to depend on yourself in } \\
\text { studying }\end{array}$ & 84 & 5 & 11 \\
\hline TBL helped you study more deeply & 74 & 5 & 21 \\
\hline TBL helped you be prepared for your final exam & 52 & 11 & 37 \\
\hline Mark distribution of TBL was good & 73 & 11 & 16 \\
\hline TBL helped you know your classmates better & 89 & 0 & 11 \\
\hline $\begin{array}{l}\text { Felt it was difficult to study the material on your } \\
\text { own }\end{array}$ & 47 & 16 & 37 \\
\hline Needed more time to prepare for the material & 79 & 21 & 0 \\
\hline Felt that there was not enough time for IRAT test & 58 & 10 & 32 \\
\hline $\begin{array}{l}\text { Felt that the IRAT represented the material you } \\
\text { studied }\end{array}$ & 67 & 5 & 28 \\
\hline $\begin{array}{l}\text { Preferred to have supervised and scheduled } \\
\text { sessions in time table for material preparation }\end{array}$ & 95 & 0 & 5 \\
\hline Would use this method in other courses & 69 & 15 & 16 \\
\hline Recommend TBL to other students & 74 & 11 & 16 \\
\hline Like to have TBL as part of every course & 42 & 31 & 26 \\
\hline Believe in team-work & 78 & 11 & 11 \\
\hline TBL changed the way you now study & 42 & 21 & 37 \\
\hline
\end{tabular}

\section{Figures}




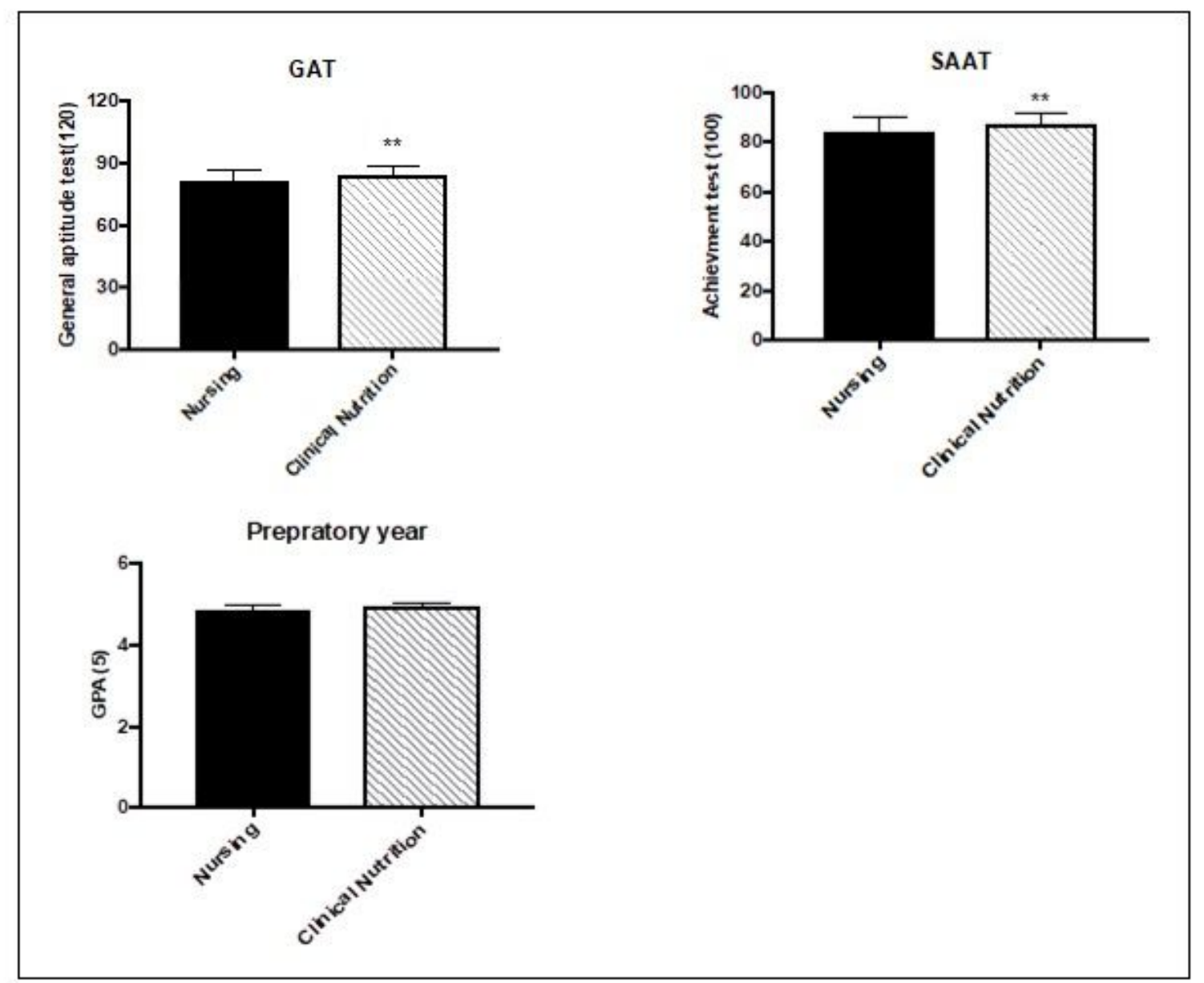

Figure 1

Comparing entry exam scores for Clinical Nutrition and Nursing students 


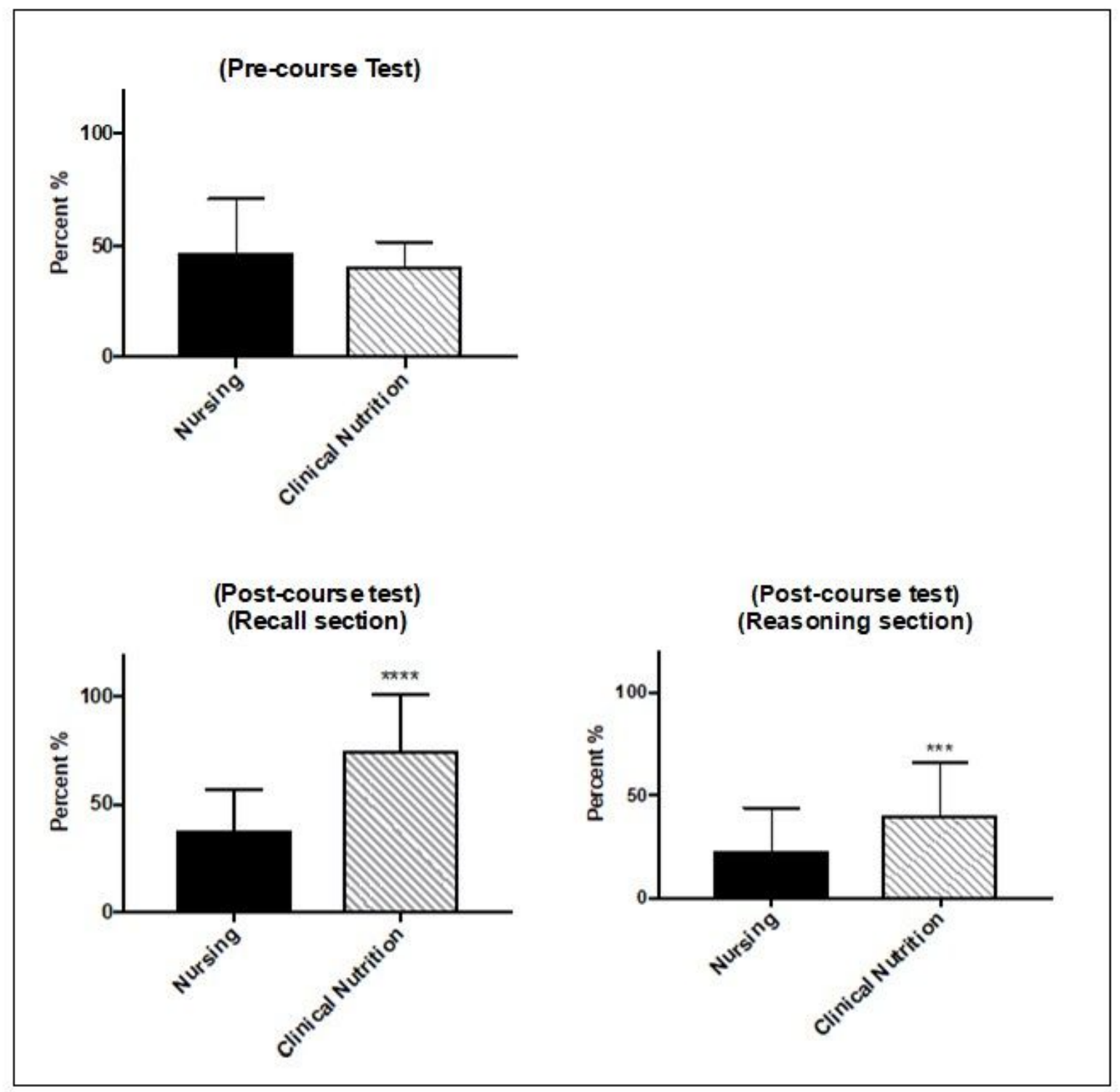

Figure 2

Comparing Pre and Post course test results for Clinical Nutrition and Nursing students 
Figure 3. Comparing Pre and Post course test results within each group
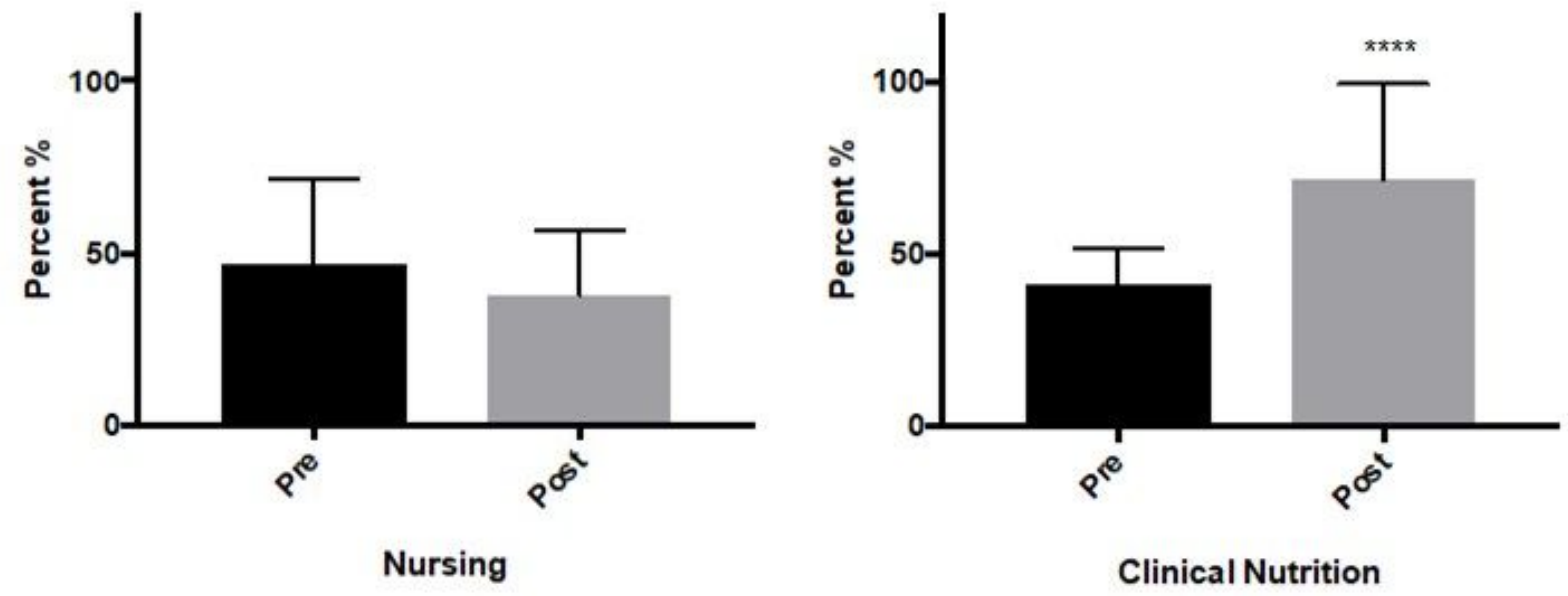

Figure 3

Comparing Pre and Post course test results within each group

Figure 4. Comparing NA final test results for Clinical Nutrition and Nursing students

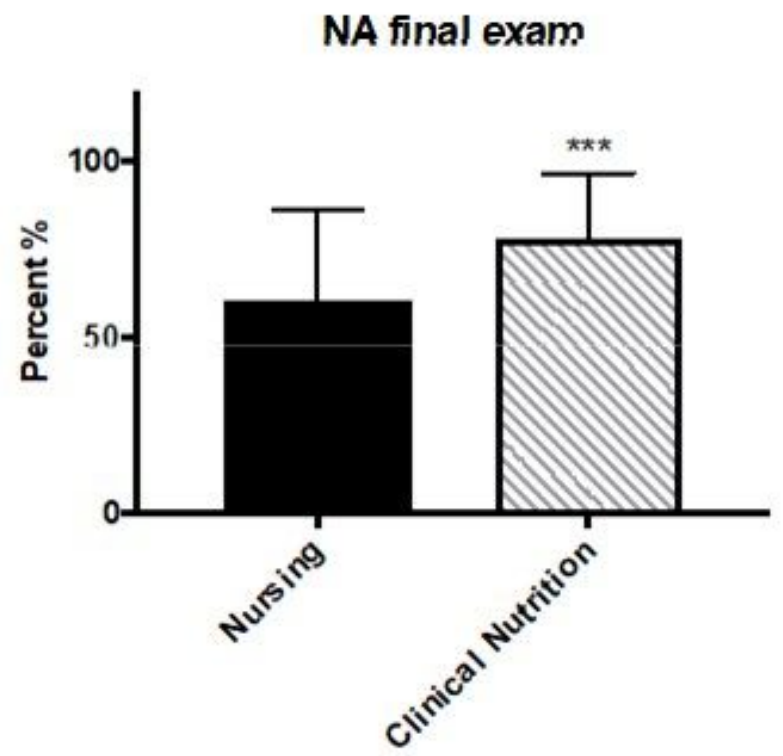

Figure 4 
Comparing NA final test results for Clinical Nutrition and Nursing students

Page 31/31 